\title{
Electronic Collaboration of Strategic Performance Management System (SPMS), Normative Funding (NF), and Drganizational Performance Indicator Framework (DPIF) for Technological University of the Philippines
}

\author{
Dr. Joel B. Mangaba \\ Professor, College of Computer Science, University of Makati \\ dr.jmangaba@gmail.com
}

Date received: July 31, 2017

Date received in revised form: October 2, 2017

Date accepted: October 9, 2017

Recommended citation:

Mangaba, J. B. (2017). Electronic collaboration of Strategic Performance Management System (SPMS), Normative Funding (NF), and Organizational Performance Indicator Framework (OPIF) for Technological University of the Philippines. International Journal of Computing Sciences Research, 1(2), 66-81. doi: 10.25147/ijcsr.2017.001.1.13.

\begin{abstract}
Purpose - The study of developing an integrated performance management aims to link planning, budgeting, and accountability elements of the performance management cycles in the university and to attain the effort of the GoP to develop a unique model of performance-based budgeting known as the Organizational Performance Indicator Framework (OPIF) in collaboration with other models of performance management Strategic Performance Management System (SPMS) and Normative Funding (NF) used by the university. To support the requirements for different agencies, this study aimed to develop and implement an Electronic Collaborative System that would contain the graphical user interface (GUI) and database definition and manipulation for the computerization on the implementation of SPMS, NF, and OPIF as one.
\end{abstract}

Method - To meet the efficiency and effectiveness of the system, System Development Life Cycle was used as the method of developing the system because of the practicality of its stages to follow from an initial data gathering through maintenance of the completed project. Series of performance tests under different conditions were conducted to measure the functionality, reliability, usability, and efficiency of the software project.

Results - The overall mean 4.16 gives the general interpretation that the study is accepted. This is the result of the mean scores per respondents from different criteria such as functionality, reliability, usability, and efficiency. The average mean ratings of possible users, IT experts, and personnel of the Planning Office are 4.50, 3.97, and 4.00, respectively.

Conclusions - The findings of the study proved that the developed software is acceptable based on the indicators.

Recommendations - The recommendations of the evaluators given based on the analysis of the study are: to conduct more tests in order to improve the efficiency of the system and in order to identify the possible enhancement of the functionality; to conduct an in-depth study to test whether the system project developed for TUP can be integrated to the existing system like ERS and Portal; maintain the system and monitor possible errors that were not anticipated in 
the previous study; and to conduct other researches with other SUCs for the possible implementation of the system in a national level with consideration on the availability of IT infrastructure.

Practical Implications - This study can be used by different SUCs sectors in decision making on how to better improve the performance of the institution aligned with the Success Indicators assigned to academic and can be easily validated and verified with the requirements of CHED and DBM. The collaboration of the requirements allows greater coordination between and among the management and the academic personnel.

Keywords - performance management, collaboration, system development life cycle, information system

\section{INTRODUCTION}

Management of the performance requirements of an organization using the existing procedures and policies to improve the effectiveness and efficiency of the system including the availability of technologies is a major challenge for information system. This is because of the considerations of the existing procedures and policies that should collaborate and consolidate each organization's entity that could meet the goals set for the evaluation of outputs. Another consideration in designing a system is the knowledge requirements in Information System (IS) which consists of software, hardware, people, data, and procedures. It is expected that information systems designed to support business processes and operations could also provide data to, or accept data from, systems focused on business decision making (O’Brien \& Marakas, 2011). It is also important to consider in a wider view of Management Information System (MIS) planning for, development, management, and use of information technology tools to help people perform all tasks related to information processing and management. People use technology to support the goals and objectives of the organization as driven by competitive pressures and determined by appropriate strategies (Haag \& Cummings, 2013). Correspondingly, corporate governance is concerned with holding the balance between economic and social goals and between individual and communal goals (Cadbury, 2006). According to Kloot and Martin (2000), performance management systems in local government use the four dimensions of the balanced scorecard: financial, community, internal business processes and innovation and learning. It shows how the focus in this system of local government has been on the results of council work, i.e., financial performance and to a lesser extent on how the community views performance.

To provide the balance between economic and social goals and between individual and communal goals, the Government of the Philippines (GoP) has invested significant time and effort to develop a unique model of performance-based budgeting known as the Organizational Performance Indicator Framework (OPIF). Improving service delivery in an environment of shrinking revenues and high mandated expenditures heightens the need for value for money which requires a focus on agency performance. Therefore, the short-term focus should be on improving operational efficiency at the agency and sector level to improve value for money as stated in the Civil Service Commission of the Republic of the Philippines (2014). According to Atkinson, most companies use formal performance measurement systems that are extensions of their financial reporting system because they believe that the practice generally regarded as reliable and consistent, thereby giving a solid foundation for developing reward and accountability (Atkinson, Waterhouse, \& Wells, 1997).

Improvements to operational efficiency can still be achieved through an integrated performance management framework, with OPIF at the center. An integrated framework would see national government departments using OPIF to manage on a performance basis by cascading their existing work on log frames and performance indicators down through departmental planning, individual performance agreements, and annual reporting. According to Hart (1992), the framework is based on the varying roles top managers and organizational members play in the strategymaking process and it goes beyond existing strategy process models by contrasting these roles and illustrating their interaction. In addition, according to Agranoff (2005), to approach solutions to today's problems reasonably, one must extend the boundaries of the agency and thus the governmental jurisdiction, working together with others toward solutions. In this era of public performance, agencies are also expected to achieve results. The problem is that agency performance depends on the engagement and actions of organizations external to the government.

Improving operational efficiency through an integrated performance management framework is far more achievable in the short-term basis. Building on existing pockets of good practice, and capitalizing on the momentum in some agencies like the Commission on Higher Education (CHED) and Civil Service Commission (CSC) of the 
Philippines that has been generated by the process of developing log frames and performance indicators and tapping into the CSC's Strategic Performance Management System (SPMS) initiative and CHED Normative Funding is therefore a strong basis for future reform. As stated in the study of Dess and Robinson (1984), strategic management researchers often encounter problems obtaining objective measures of selected aspects of organizational performance that are reliable and valid. With privately-held firms, such data are frequently unavailable. With conglomerate business units, all or parts of such data are inextricably interwoven with corporate-wide data.

Normative funding refers to the application of a set of prescribed objective criteria and norms that are designed to promote and reward quality instruction, research and extension services, as well as financial prudence and responsibility. It is aimed for an organization to accomplish the following: further rationalize the allocation of funds to SUCs; improve delivery of service in the fields of instruction, research and extension; harmonize the programs and course offerings of SUCs to the national thrusts and priorities; encourage quality teaching, research, and extension services; encourage SUCs to improve cost recovery measures, and practice fiscal prudence and maximize resources. Normative funding (NF) is being implemented through Department of Budget and Management (DBM)CHED Joint Circular No. 2, s. 2004 dated August 3, 2004. Application of NF in the Allocation of Expenditures to State Universities and Colleges (SUCs) starting FY 2005 Budget and Thereafter. It is a legal basis for Normative Funding Formula (NFF) with the objectives to rationalize SUC course offerings in the light of national priorities, to encourage quality teaching, to strengthen research and extension services, and to encourage SUCs to improve cost recovery measures, to practice fiscal prudence and maximize resources.

The phase of developing an integrated performance management framework targets linking planning, budgeting and accountability elements of the performance management cycles. The significant impact of the Performance Management System (PMS) occurs when there are incentives attached. Alongside requiring agencies to submit performance agreements, the chairman of CSC also holds internal "budget hearings" where divisions had to justify their budget in terms of the outputs they were to deliver (Duque, 2012). The CSC has the ability to do this because they are a fiscally-autonomous constitutional organization and therefore are not subject to the same tight input controls.

While the DBM and CSC have been working closely on improving governance through the rationalization planning process, there is a substantial disconnect between the design of PMS and OPIF. There is a risk of greater fragmentation on the process if DBM and CSC continue to treat OPIF and PMS as two separate reforms. Closer collaboration and the development of an integrated performance management framework as suggested in this paper should lead to greater alignment between the two reform processes plus the integration of NF. Building an integrated performance management framework should strengthen the internal management practices in agencies, and give the DBM the confidence they need in order to devolve responsibility and authority to agencies to manage inputs.

Developing an integrated performance management framework at the center and cascading this into agencies will achieve clear line of sight between planning and budgeting within agencies (operational efficiency and allocative efficiency at the sector/agency level); better preparedness for the devolution of responsibility and control over resources that will come with a fully-operational performance-based budgeting system; more confidence in the ability of agencies to manage the requirements on a performance basis; more time to strengthen their capacity to monitor and evaluate agency performance-skills required for the change from a culture of rules-based and input controls to a culture of performance-based management; and consolidation of fragmented performance management practices in agencies and other performance management initiatives.

The TUP is one of the SUCs bounded with requirements enumerated above. The development of a system that will handle the collaboration of different information from different requirements will result to a more organized system that could communicate and store and retrieve information. This is the reason behind the approval of the development of an electronic system that will manage the collaboration of different systems was approved. The university complies with the conditions of good governance as set by National Budget Circular 542 issued by the Department of Budget and Management. TUP follows the template for OPIF provided by the DBM, SPMS provided by the CSC, and NF provided by the CHED. The university has 4 campuses located in Manila (flagship), Taguig, Cavite, and Visayas, each with 4 assigned personnel in planning department. It also has two satellite campuses located in the province of Quezon. 
Currently, the planning office is responsible for consolidating all information needed for SPMS, NF, and OPIF requirements and provides different reports for external clients/agencies like CSC, CHED, and DBM. Different sectors like VP for Research and Extension (VPRE) with three (3) personnel, VP for Academic Affairs (VPAA) with eleven (11) personnel and a total of 39 personnel for colleges and 343 faculty members, VP for Administration and Finance (VPAF) with twelve (12) personnel, VP for Planning, Development and Information Systems (VPPDIS) with eight (8) personnel need to comply with the requirements of the Strategic Performance Management System (SPMS) by providing their accomplishment reports (ARs) and commitment ratings for the identified success indicators (SI) or performance indicators (PI) in a cascaded process from University-wide for Organizational Performance Commitment Rating (OPCR), Division Performance Commitment Rating (DPCR), Head Performance Commitment Rating (HPCR), and Individual Performance Commitment Rating (IPCR).

The planning office is experiencing the tedious process of manually consolidating the reports from different offices and colleges, including other campuses, as inputs for the OPIF and NF templates provided by the DBM and the CHED respectively. These templates are sources for other reports. As a result, the generation of summary reports from the templates takes a lot of time. Different pieces of information from various sources are submitted repeatedly even without updates which create data redundancy. There is no way to validate and verify the inputs for the distinction of report generation because the reports can be used to prepare requirements for SPMS, NF, and OPIF. The university has no specific database designed to store submitted reports where data collection for later use is not possible. With the problems cited, the researcher intended to develop a system that will organize and provide possible solutions.

\section{OBJECTIVES OF THE STUDY}

The general objective of the study is to develop and evaluate an Electronic Collaboration of SPMS, NF, and OPIF System for TUP.

Specifically, the study aims to

1. design an interface that will facilitate the collaboration and consolidation of different subsystems like SPMS, NF, and OPIF into one system including the generation of necessary reports;

2. design a database structure that will handle definition and manipulation of relational database management system to reduce data redundancy and increase data security and reliability; and

3. test and evaluate the system in terms of functionality, reliability, usability, and efficiency.

\section{SIGNIFICANCE DF THE STUDY}

The study will help the university to conform to the Government's goal to monitor the performance and evaluate the output for appropriate rating. With the electronic system, TUP will be benefited with an easier consolidation of the requirements needed for the submission to different agencies like CSC, DBM, and CHED. For CSC, the SPMS system is expected to contribute for the easy monitoring of the productivity and accountability of every employee with the specified MFO for the university, this success indicators defined in OPCR will be cascaded down to the IPCR. It is designed to link individual performance vis-à-vis the university's vision, mission, and strategic goals. This applies to all faculty members regardless of their employment status and administrative employees including those on casual or contractual status. It is a framework which consists of strategies, methods and tools to ensure the effective execution of the functions of the various offices as well as to assess their performance. In addition, the outcome of the faculty performance is a mechanism that ensures every employee's attainment of the objectives set forth by the school during its strategic planning as well as that of the university's operational planning meetings. For CHED, the NF system is used to verify the performance of the universities and to validate the budget for output to be recommended to the DBM. There are provided templates by the CHED in excel format for different entries and output concerning the employees records. There are also templates for the university's population for the DBM. The reporting of outputs uses the templates provided by the DBM in excel format. 


\section{LITERATURE REVIEW}

Management Information System (MIS) has a significant role in enhancing strategic and tactical planning as presented by Akram (2011). According to him, in the Kingdom of Bahrain, MIS is the key factor to facilitate and to attain efficient decision making in an organization. In his research, he explored the extent to which management information systems implemented to make successful decisions at two selected financial organizations. The regression analysis revealed that Tactical planning is found to have no effect on Decision Making, while Strategic planning has a clear effect on the Decision Making Effectiveness in both organizations. In addition, method of an intensive interactive indicator development process between policy makers and researchers has so far proven successful (Ten Asbroek et al., 2004) and the emergence of socially responsible investing has led to the development of a large number of methodologies for rating corporate social responsibility and to a growing body of research exploring the link between environmental and financial performance Delmas, Etzion, and Nairn-Birch (2013).

The idea of integrating manual procedure and information technology in the process gives direct impact to the strategic planning of the management in Brazilian organizations. This concept was proven in a research conducted by Tonelli, Bermejo, \& Zambalde, (2014). In the research, a method that integrates Balanced Scorecard (BSC) concepts and IT strategic planning (ITSP) processes was applied in two organizations in order to verify contributions of Balanced Scorecard regarding the identified ITSP problems. The development of this work was realized in qualitative, exploratory research based on two case studies. The results showed that the use of BSC contributed directly to work with IT strategic planning challenges and involved middle management, multifunctional teams, and top management support, all beyond the IT boundaries.

According to DeNisi and Smith (2014), the idea of studying methods to improve performance at work which is concerned with individual-level performance has been a long history in management and organization. In addition, despite the importance to researchers, managers, and policy makers of how information technology (IT) contributes to organizational performance, there is uncertainty and debate about what we know and don't know (Melville, Kraemer, \& Gurbaxani, 2004). As opined by Irving, Higgins, and Safayeni (1986), computerized monitoring is associated with perceived increases in office productivity, more accurate and complete assessment of workers' performance, and higher levels of organizational control.

Another study that shows the application of MIS was conducted in five provinces covering 90 randomly selected continuing barangays and 68 randomly selected non-continuing barangays in the Philippines in relation to its effect on the decision making of the government officials. It was determined in the study that the institutional and individual factors contributed to the use of a Barangay Management Information System (BMIS). The identified significant individual factors that influenced the barangays' decision to sustain BMIS were the system's userfriendly features, ease in managing the BMIS software, and usefulness of data generated in performing the functions of the local government officials. The significant institutional factors that contributed to sustaining a Local Information System (LIS) were the active participation of the Barangay Council members in data management; the availability of budget and equipment; the presence of municipal and technical support from the municipalities and state universities and colleges; and the utilization of data in the submission of administrative reports, situational analysis for the preparation of plans, monitoring and targeting of beneficiaries; and the issuance of local ordinance for the adoption of LIS. Recommendations included strengthening the process of policy preparation at the local level; organization of the LIS team; creation of positions for Information or Investment Officers; crafting of ordinances to support the budgetary requirements; and establishment of partnerships between SUCs and the LGUs (Maneja \& Tandang, 2012).

According to Lausa (2016), the important role IT plays in educational institutions is unquestionable and it is regarded as a critical factor for innovation for growth and survival. Based on the study, there is a significant relationship between the operational efficiency of information technology and organizational performance of SUCs. However, a significant relationship between operational efficiency and organizational performance of SUCs in instruction does not exist while a significant relationship exists in research, extension and production. 


\section{METHODDLDGY}

This chapter presents how key phases and numerous activities within each phase in systems development life cycle (SDLC) as a methodology used is applied. This is to ensure in this study that all requirements are met during the development of the system and that uniform privacy and security practices for system users are established. The chosen methodology is best applied in a big project that considers the 3 different subsystems that were developed for almost 2 years.

Initially, as part of the planning, the focus of the study was to develop an electronic Strategic Performance Management System (eSPMS) that will help the university meet the requirements of the CSC for their quarterly report. The idea is to make the submission and approval of reports done in a computerized manner in a network setup. During the meeting with the director and other personnel of the Planning, Development and Information Systems (PDIS) office, the consolidation of different requirements from NF, OPIF, and SPMS was suggested because this is what they need to comply with the requirements of the CHED, DBM, and CSC without having redundant collection of information from different offices - the common problem encountered by different offices. It was also discussed that if there will be one database where information can be stored and retrieved, there will be an ease for them to meet deliverables on time. All the information needed including sample forms and templates were provided. There was a series of meetings with the PDIS personnel for the verification, clarification, and validation of the project's requirements. With all the requirements, there was a change in the focus of the study which becomes wider in scope that covers 3 different subsystems.

Analysis of system's requirements including all the parameters of different subsystems was not an easy activity because of different ideas and instructions that are not clear. To easily analyze the requirements of the project including its technicality, meetings were conducted with the director and other personnel of the UITC, different colleges, registrar's personnel, and a member of faculty members. After gathering all the information, there were still questions that were not answered. Fortunately there was a 2-day orientation conducted on August 18 and 19, 2014 focusing on the briefing and reorientation on the NF, OPIF, PBB, and other reportorial requirements headed by the PDIS office. All representatives of the different offices including other SUCs campuses and satellites were present. There was also a workshop on how the forms and templates given by different sectors like CHED, DBM, and CSC may be used. With the approval of the director of the PDIS and with the help of the adviser, the chance to attend in 2 days, experience and clarify the system requirements, join the workshop, and conduct interviews was given.

To meet the requirements for each subsystem, all instructions for data entries and outputs were also studied. Each subsystem has its own instruction provided by CHED for NF, DBM for OPIF, and CSC for SPMS (please see attached). An intense data analysis was applied and resulted to the lessening percentage of data entries for both NF and OPIF. In NF, the data entry was lessened to $78 \%$ while in OPIF is $52 \%$. Common data were identified from these two requirements table-by-table and cell-by-cell.

In design, data collection and consolidation, all attributes from different requirements were identified. There are more than 80 tables in the database design to facilitate the data manipulation of the whole system for the storage of data/information from data entries in SPMS, NF, and OPIF. Related fields are connected using primary keys and foreign keys to make sure that there are relationships. Normalization was applied in designing the database to avoid data redundancy for deletion and updating of records. The first normal form of the database is the consideration of all fields from different tables. The second normal form removes all non-atomic data and primary keys that were identified as a unique key where all atomic fields are related. The third normal form creates all independent and dependent variables and foreign keys were that identified to retain the relationships with other tables. Data Definition Language was used to create the database and tables while Data Manipulation Language was used to easily update data both in storing and retrieving of necessary data/information usually for output generation. To easily view the records based on target, SQL was used. The use of "where" clause was applied to define the condition of the queries by checking the primary key and foreign key values. The condition must be satisfied to produce data. To define the linkages of tables, join clause was used including sub-queries for specific data. To manipulate data, insert and delete clauses were used. The insert clause was used to store data while delete clause was used to remove data from the database. To alter the information, update clause was used. 
For user friendly and adaptability of the system, all forms used were analyzed to conform to the required fields of the GUI. To easily understand the flow of the system, Figure 1 below shows the system's architectures in the organization's view and in the system's view. The system's structures consider database in the cloud for the submission of deliverable of other TUP campuses. Also, the collaboration of the 3 subsystems was considered. All data or information are processed in the main campus because the VPPDIS manage all the deliverables needed to submit to CSC, CHED, and DBM.

Testing is intended to show that a program does what it is intended to do and to discover program defects before it is put into use. This may take planning, execution, checking, and making actions (Perry, 2007). There were 3 stages of testing procedures applied; development, release, and user. To determine that each module is working based on the requirements, unit testing was used. Each module was validated based on the correct inputs from maintenance to settings. After setting all the parameters, other modules were tested based on the relationship of modules. To verify that the system units or pieces of code written for each module function properly when integrated into the total system, a system testing was applied. Prior to user testing, a separate testing team tested a complete version of the system before it was released to users. To determine if the system satisfies the requirements of the university and to find out it is able to perform correctly, user acceptance testing was applied. The director of the PDIS and administrators of different colleges tested the system whether it conforms to the functional requirements. IT experts also tried to test the system based on its capacity.

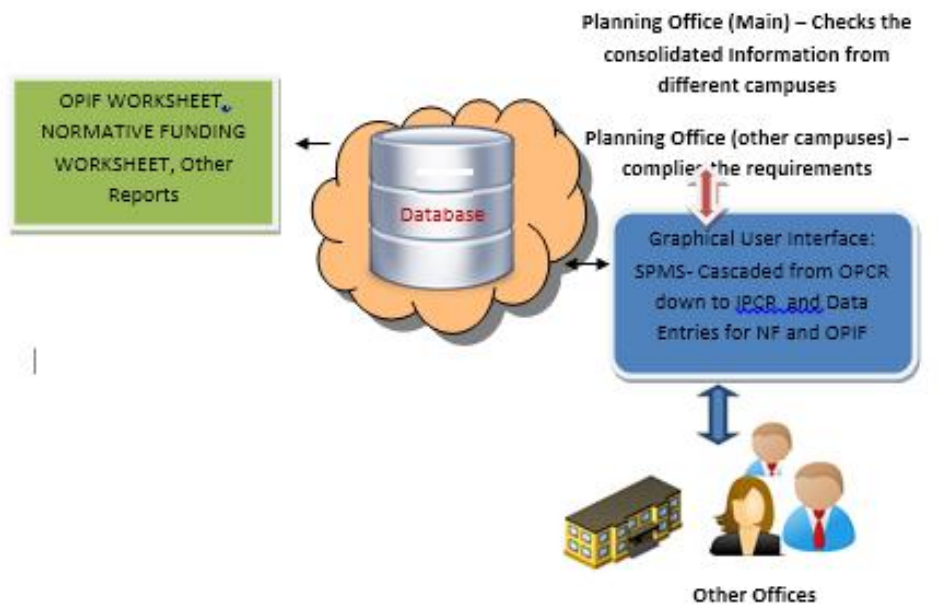

Figure 1. System's Architecture Design - Organization

The system was evaluated for its functionality with the following criteria: the software has the ability to interact with the system environment, the functions required for the system are implemented, the functions included in the system are fully functional, and the software has provision to prevent unauthorized users from accessing the system. The system was evaluated for its reliability with the following criteria: the software encounters no error or bug, the software does not bog down despite the fact that errors or bugs are encountered, and the software can restore to its normal operation when failure occurs. The system was evaluated for its usability using the following criteria: the software is easy to use, the software is easy to operate, and the software displays instructions that are easy to understand. The system was evaluated in its efficiency using the following criteria: the software can easily execute the requests, the software uses minimal system resources, and the software determines the errors or bugs encountered during operation.

The considerations made to select the evaluators/testers of the system are the following:

a. Knowledgeability on the Performance Management System (SPMS, NF, OPIF)

The best people that can evaluate the system are from the Planning Office with eight (8) personnel, headed by the VPPDIS. The team also presented some cases from other campuses like Taguig, Cavite, and Visayas. Former directors and personnel were asked to evaluate the system by executing the system and with the use of the instrument to verify and validate the system requirements. Possible users like deans, college secretaries, and faculty were also asked to test the system based on their level of administrative 
capacity and participation on the delivery of the requirements of SPMS, NF, and OPIF. To verify and validate, 2 colleges, the CIT and the CIE tested the system with 11 and 6 personnel including the deans.

b. Knowledgeability on the technicality of the developed system based on the requirements.

Personnel from UITC, which is part of the VPPDIS, were asked to verify the output of the system in terms of the technical part of the system. They also represented the office of the administration under office of the president of the university.

c. Some IT experts were also chosen to give feedback on how to improve the system as a whole.

To implement the system, a demonstration of the system was conducted to the PDIS. The system's functionality was simulated per module basis from maintenance to process. To be guided with the system flow, user documentation that highlights how to use the system will be provided. One of the possible guides for the users is a guidance that will provide a video on the step-by-step simulation of the system flow.

Part of the plan to make the system more useful is its network set-up. The system will be implemented in a network set-up where there will be a main server available to be accessed by different offices using a router. Each office also has its server. To secure the database, each college/office was provided its own database back-up to avoid data loss in case one server fails. All other servers are connected to the main server. As agreed, the UITC office will be responsible for the security of the system by providing access privileges of the developed system. This can be done using the user settings where different users based on their level can be given or assigned its own capacity to access the system. The implementation of the system will be done in a pilot setting for TUP Manila. It is suggested that parallel implementation will be applied where both the old and new systems will be used until there is an assurance that the new system performs correctly. It is expected also that during the implementation, documentation of areas for improvements are done for the maintenance consideration. It can also be implemented on subsystem before the remaining subsystems are implemented. This is to ensure that the system as a whole will work accordingly.

To test and evaluate the project with its target output, the evaluation instrument was used. The numerical rating is from 1 to 5 with the following equivalent interpretation: 1 - Not Acceptable, 2 - Fairly Acceptable, 3 Moderately Acceptable, 4 - Acceptable, and 5 - Highly Acceptable. The indicators used are functionality, reliability, usability, and efficiency. The indicators were evaluated based on the parameters presented on the table 1.

Table 1. System Parameters and Indicators

\begin{tabular}{|c|c|}
\hline Parameters & Indicators \\
\hline Functionality & $\begin{array}{l}\text { - the software was has the ability to interact with the system environment } \\
\text { (interoperability) } \\
\text { - the functions required for the system (compliance) } \\
\text { - the functions included in the system are fully functional (accuracy) } \\
\text { - the software has provision to prevent unauthorized users from accessing the system } \\
\text { (security) }\end{array}$ \\
\hline Reliability & $\begin{array}{l}\text { - the software encounters no error or bug (maturity), } \\
\text { the software does not terminate despite errors or bugs are encountered (fault } \\
\text { tolerance), } \\
\text { - the software can restore its normal operation when failure occurs (recoverability) }\end{array}$ \\
\hline Usability & $\begin{array}{l}\text { - the software is easy to use (easy to learn), } \\
\text { - the software is easy to operate (operability), } \\
\text { the software displays instructions that are easy to understand (understandability) }\end{array}$ \\
\hline Efficiency & $\begin{array}{l}\text { - the software can easily execute the requests (time behavior), } \\
\text { - the software uses minimal system resources (resource behavior), } \\
\text { - the software determines the error or bug encountered during operation (analyzability) }\end{array}$ \\
\hline
\end{tabular}

The project was evaluated by different groups of people that could use the system and experts to the field of system development like TUP faculty, college secretaries, planning personnel, and IT experts. The evaluation 
procedures were applied for each indicator stated in the instrument used. To determine the descriptive analysis of data, the mean or average of indicators per type of evaluator was computed. The overall rating of the results is the average of each group of people who evaluated the system.

In system function, each module was tested on how it works. All generation of reports were tested on the efficiency of the system. It can monitor and generate reports based on the requirements necessary to be provided by colleges. SPMS was tested in a cascaded flow of the reference from OPCR to IPCR for identifying Success Indicator and IPCR up to OPCR for approval. The same procedure was applied when identifying and approving actual accomplishments. OPIF and NF were populated as targeted cells in a worksheet template that can be accessed from the stored data by different colleges. Some inputs were tested using the graphical user interface provided to the users. In terms of security, different possible users from different levels of privileges were tested by trying to access only modules that are permitted by the administrator. For system reliability, each module was tested in a stress test to check the validity of data and checked that no error will occur in the error handling. The system was also tested with its maintenance to determine if the records could be added, edited, and deleted.

In system usability, the modules were tested if the system could provide appropriate instruction or notice if erroneous pieces of data are entered. This is to ensure that the system has the capacity to check the correct entry of data to minimize invalid data. In System's efficiency, each module was tested by executing the program. Also, the module provided expected functions and outputs for each module in each subsystem. The data stored was retrieved and used by different subsystems. This proves that the consolidation and collaboration of data are met based on the objectives of the project.

Sectors, Divisions, Departments, and Individual employee were expected evaluators of the system functionality. The project was evaluated with sufficient number of respondents, composed of VP for Planning, Development and Information System, Academic heads, Department heads, college secretaries, and Information technology experts. From IT experts, the developer asked IT Senior Analyst, VB.Net Developer, Web Developer, and Programmers.

The evaluation procedure includes the following:

1. Each evaluator is given an evaluation instrument form.

2. Each evaluator is given a chance to use the software product to test and evaluate its performance. The testing is done based on the flow of the system from maintenance in order to process the data entries to expected outputs.

3. The system is evaluated carefully by the experts with regard to the evaluation form given to them. Each evaluator was given an evaluation tool while testing the system.

4. The results were tabulated and computed using the mean range formula to conclude if the system is acceptable. The evaluation instrument would be given to expected users that would be selected randomly to act as respondents for the final evaluation of the system. The criteria includes the following: functionality, reliability, usability, and efficiency (Table 1).

Each criterion would be rated on a scale of 1 to 5, with five (5) being the highest and one (1) being the lowest. The system criteria mentioned above is rated using the Likert's Scale shown in Table 2.

Table 2. Likert's Scale

\begin{tabular}{cl}
\hline Numerical Rating & \multicolumn{1}{c}{ Equivalent } \\
\hline $4.51-5.00$ & Highly acceptable \\
$3.51-4.50$ & Acceptable \\
$2.51-3.50$ & Moderately Acceptable \\
$1.51-2.50$ & Fairly acceptable \\
$1.0-1.50$ & Not acceptable \\
\hline
\end{tabular}

The pieces of data that were gathered would be tabulated and computed with accuracy of output for descriptive analysis. The Likert's scale was used to evaluate the acceptability of the system. The expected output would show the mean and standard deviation that is used to determine the performance and acceptability of the system.

The following sample data/reports from different offices of TUP were gathered: Performance Indicator Matrix, Templates of Normative Funding, Templates of Organizational Performance Indicator Framework, Sample Reports 
of OPCR, SPCR, DPCR, HPCR, and IPCR, Definitions, Instructions and Examples for SUCs OPIF, NF Instructions Guide, and SPMS. The Performance Indicator Matrix is the summary of the performance measures categorized in Operation, Support to Operation (SO), and General Administration and Support Services (GASS). From the table, the information from different forms used could be an entry to not only one performance management system. This matrix is the summary of the analysis of the Planning office after a thorough study on the different forms/templates provided by CHED and DBM and some requirements by the CSC.

\section{RESULTS AND DISCUSSIDN}

The results of the study based on the methodology used during the entire development of the project are presented in this section. Electronic Collaboration and Consolidation system of SPM, OPIF, and NF for TUP was developed to easily perform tasks especially in producing information that are needed for consolidation. It is a computerized system supported by a database management system for data definition and manipulation. The system was created using Visual Basic.Net and Visual Basic for applications as the programming language, SQLYog for the database design, and embedded crystal report for the reports design.

The features of SYSTEM include a security login for the access to the system and security maintenance to modify user's account or access, a data manager that would allow the user to enter data and maintain system's setup, and a SPMS with a cascading process for OPCR, SPCR, DPCR, HPCR, and IPCR from top to bottom and vice versa. The category could be selected, goals and success indicators for each level. The actual accomplishment is rated using the matrix provided by the CSC. The quantitative part is automatically computed while some parts are data inputted based on the prerogative of the evaluator. The average rating for each employee is automatic and summarized.

The NF modules for different offices contain the Capsule Institutional Profile, Profile for each curricular program, Number of Programs by Campus, Enrolment per Program, Enrolment per Campus, New Students by Campus, Lab Student Contact hours by Campus, Lecture Student Contact Hours by Campus, Number of Graduates by Campus, Graduates per program, Number of Programs by Major Discipline, Enrolment by Discipline, Enrolment per Program, New Students By Discipline, Lab Student Contact Hours by Discipline, Lecture Student Contact Hours by Discipline, Number of graduates by Discipline, Individual Faculty Workload Report, Profile of Each PreCollegiate faculty, Profile of each Tertiary Faculty, Number of Full-time Personnel by Campus, Basic Salaries by Campus, Number of Graduate Degree Holders by Faculty Group, Faculty Degrees Matching their teaching Discipline, Number of Full-time Personnel by Salary Grade, Appropriation, Allotments and Expenditures, Income, Internal Operating Budget, and Research Inputs and Outputs,

The system has OPIF templates which include OPIF weights per program level and discipline, enrolment per discipline $-1^{\text {st }}$ semester, enrolment by major field of study, percentage of enrolment by major field of study, graduates by discipline, graduates by major field, percentage of graduates in each major field, number of students $\mathrm{n}$ year ago, percentage graduation rates per discipline, enrolment by campus and by program level, number of programs accredited, Licensure exam passing rates, FTE Faculty by highest and earned degree, SUC beginning and ending balances, SUC income by source, externally-funded merit scholar, lecture and laboratory units, FTE students, and training programs and trainee-days. Report generation capabilities for Physical Performance Reports, Accomplishment Ratings using Excel application are also found in the system. Some of the screenshots in the system like sample SPMS module in figure 2, sample NF module in figure 3, and sample OPIF module in figure 4 are shown below. 


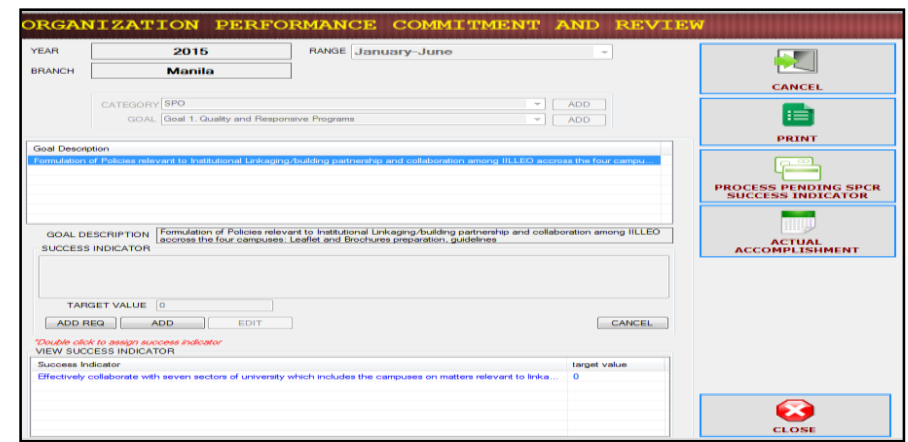

Figure 2. Sample SPMS module

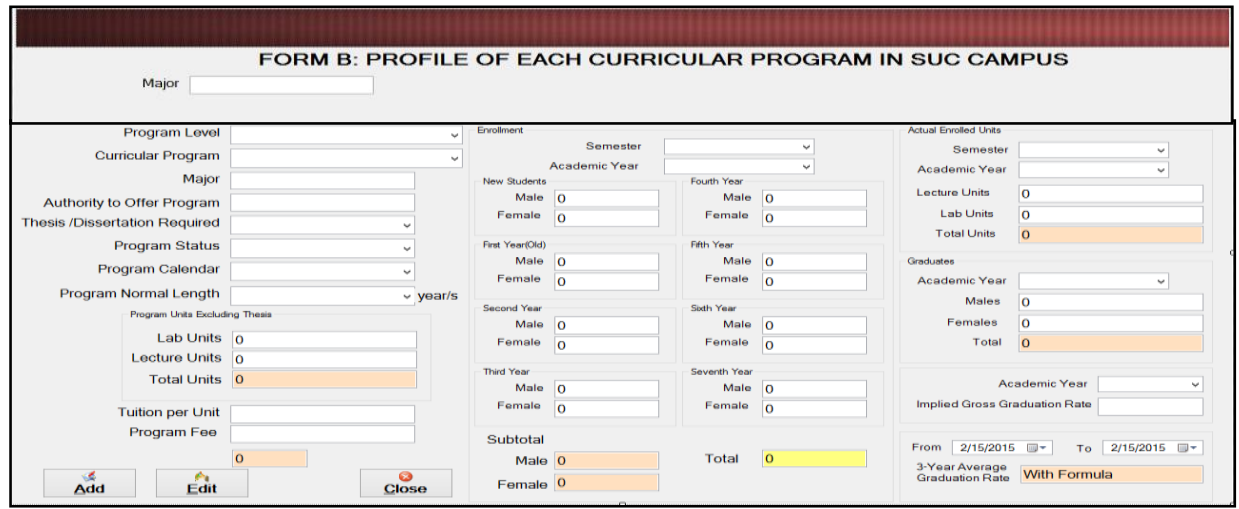

Figure 3. Sample NF module

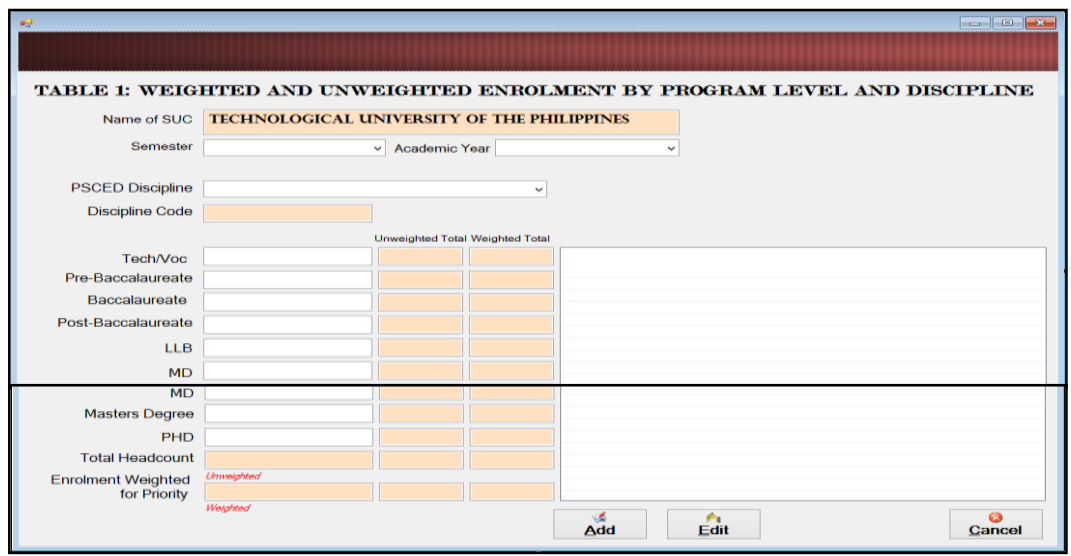

Figure 4. Sample OPIF module

The results of the evaluation conducted shown in the table 3 for the developed system for TUP have gained an overall mean of 4.16 with a descriptive rating of "Acceptable". The ratings for criteria are as follows: Functionality, 4.19; Reliability, 4.18; Usability, 4.10; and Efficiency, 4.16. With the 4 criteria used to determine the acceptability and performance of the developed SYSTEM, all indicators are Acceptable. This proves that as far as the respondents are concerned, the system for TUP is moderately-acceptable. From the result, functionality gained the highest rating. This means that the system can easily be evaluated and rated based on its functionality because the interaction of the system can be easily determined as the user tries to use the system - the system can easily interact with the user. The requirements can be easily verified because the evaluators have knowledge on the requirements of the systems' inputs and outputs. The access to the system is based on the type of users created by the admin. Only permitted privileges can be accessed by each user; thus, maintains the security of the system from unauthorized users. 
Table 3. Summary of Mean Scores Per Criteria and Respondents

\begin{tabular}{|c|c|c|c|c|c|}
\hline \multirow[b]{2}{*}{ Criteria } & \multicolumn{3}{|c|}{ Mean Scores Per Respondents } & \multirow[b]{2}{*}{$\begin{array}{c}\text { Mean Per } \\
\text { Criteria }\end{array}$} & \multirow[b]{2}{*}{ Equivalent } \\
\hline & Possible users & IT Experts & $\begin{array}{l}\text { Planning } \\
\text { Office }\end{array}$ & & \\
\hline A. Functionality & 4.5 & 4.06 & 4.00 & 4.19 & Acceptable \\
\hline B. Reliability & 4.5 & 4.04 & 4.00 & 4.18 & Acceptable \\
\hline C. Usability & 4.5 & 3.79 & 4.00 & 4.10 & Acceptable \\
\hline D. Efficiency & 4.5 & 3.97 & 4.00 & 4.16 & Acceptable \\
\hline Overall/Grand Mean & 4.5 & 3.97 & 4.00 & 4.16 & Acceptable \\
\hline
\end{tabular}

The possible end-users have the highest mean rating among the 3 categories of respondents (overall mean rating $=4.50$, acceptable). However, IT experts and Planning Office gave an overall rating of 3.97 and 4.00 respectively that still has a descriptive rating of "acceptable". IT experts who are considered to be technical persons have the lowest mean of 3.97 among the 3 respondents because they have other views for testing the system. IT experts have the capacity to do stress test that is used to verify and validate every requirement and expected input and output of the system.

Out of the criteria used in the evaluation (functionality, reliability, usability, and efficiency) is the criterion "functionality" which obtained the highest overall mean of 4.19 followed by "reliability" with an overall mean of 4.18. The criterion "efficiency" being the third followed by "usability" being the last with an overall mean of 4.10.

Table 4 shows detailed representation of evaluation results of different evaluators stated in the discussion of the summary of the results. From Table 4, all indicators fall under the equivalent remark "acceptable". In Functionality attained the highest mark which is 4.23 for the security which means that software has a provision to prevent unauthorized users from accessing the system. This is because the system has the user setting for the possible access privileges in the modules that could be assigned by the administrator. Interoperability is next to the highest with a mean of 4.22 which means that the software could be used to interact with the system environment. This is possible because the designs used are adopted from the current set-up of TUP using different templates available from different agencies. The next is accuracy with a mean value of 4.17 which means the functions included in the system are fully-functional. This is based on the expected response of the system based on the requirements from the possible users. The last is compliance with a mean value of 4.13 which means the functions required for the system are implemented.

Second to the highest is Usability with a mean value of 4.18. The highest indicator is learnability with a mean value of 4.22 which means the system is easy to use. The design of the system follows the format given by different agencies. The next is operability and understandability having the same mean value of 4.20 with the interpretations that the system is easy to operate and displays instructions that are easy to understand. For any interruption like wrong input for confirmation, the system provides a message box that gives information on how the system responds to the action of the users. Third in rank is Reliability with a mean value of 4.16 . From its criteria, fault tolerance and recoverability have the same mean value of 4.17 which means that the software does not halt even if errors or bugs are encountered and could restore to its normal operation when failure occurs respectively.

The maturity of the software has a mean value of 4.13 which means the software encountered no error. Last is Efficiency with a mean value of 4.10. The analyzability indicator got the highest mark with a mean value of 4.17 which means the software determines the error encountered during operation. This means that the system could easily communicate and inform the users on the action to be taken if error occurs. Next is time behavior with a mean value of 4.12 which means that the software could easily execute the requests. Last is resource behavior with a mean value of 4.01 which means that the software uses minimal system resources. All the results of the evaluation for all indicators fall to acceptable. This proves that the project was considered functional, reliable, usable, and efficient. The project was highly recommended by the VPPDIS for implementation.

With the use of the system, there would be a fast monitoring from a performing and non-performing sector. It would also reduce tedious work and redundancy of reports submitted to different government agencies because of the collaborated and consolidated reports to meet the requirements of each external agency. Particularly, data entry in NF was reduced to 78 percent and in OPIF was reduced to 48 percent. The result of reduction was tested from the 
manual system. This means that from the current set-up of 32 tables, entries were reduced to 7 tables using the system for NF, and from 25 tables of data entries was reduced to 13 tables using the system. The result was achieved based on the analysis of determining common data after collaboration and consolidation was lessened. Not only the data entries were analyzed, the generated value using computation was likewise considered. From each table, only data that are required for inputs are manipulated by the user (take note also that from data entries, some are computed), others are for viewing only (this means that GUI for data entries are the only required with user's intervention for manipulation). Formulas are already set to the target cells in Excel application. The result for viewing is not necessarily computed by the system. These data could be fetched from Excel computed value since the templates are from the CHED and DBM. Some of the cells from the templates are set to compute from other cell addresses.

Table 4. Detailed Summary of Mean Scores per Criteria and Respondents

\begin{tabular}{|c|c|c|c|c|c|}
\hline \multirow{2}{*}{ Criteria } & \multicolumn{3}{|c|}{ Mean scores per respondents } & \multirow{2}{*}{$\begin{array}{c}\text { Mean } \\
\text { per } \\
\text { criteria }\end{array}$} & \multirow[t]{2}{*}{ Equivalent } \\
\hline & $\begin{array}{c}\text { Possible } \\
\text { users }\end{array}$ & $\begin{array}{c}\text { IT } \\
\text { Experts }\end{array}$ & $\begin{array}{l}\text { Supply } \\
\text { Officer }\end{array}$ & & \\
\hline A. Functionality & 4.5 & 4.06 & 4.00 & 4.19 & Acceptable \\
\hline $\begin{array}{l}\text { 1. The software has the ability to interact } \\
\text { with the system environment } \\
\text { (interoperability). }\end{array}$ & 4.5 & 4.15 & 4.00 & 4.22 & Acceptable \\
\hline $\begin{array}{l}\text { 2. The functions required for the system } \\
\text { are implemented (Compliance). }\end{array}$ & 4.5 & 3.90 & 4.00 & 4.13 & Acceptable \\
\hline $\begin{array}{l}\text { 3. The functions included in the system } \\
\text { are fully-functional (accurateness). }\end{array}$ & 4.5 & 4.00 & 4.00 & 4.17 & Acceptable \\
\hline $\begin{array}{l}\text { 4. The software has a provision to prevent } \\
\text { unauthorized users from accessing the } \\
\text { system (security). }\end{array}$ & 4.5 & 4.20 & 4.00 & 4.23 & Acceptable \\
\hline B. Reliability & 4.5 & 3.98 & 4.00 & 4.16 & Acceptable \\
\hline $\begin{array}{l}\text { 1. The software encounters no error or } \\
\text { bug (maturity). }\end{array}$ & 4.5 & 3.90 & 4.00 & 4.13 & Acceptable \\
\hline $\begin{array}{l}\text { 2. The software does not bog down } \\
\text { despite errors or bugs are encountered } \\
\text { (fault tolerance). }\end{array}$ & 4.5 & 4.00 & 4.00 & 4.17 & Acceptable \\
\hline $\begin{array}{l}\text { 3. The software can restore its normal } \\
\text { operation when failure occurs } \\
\text { (recoverability). }\end{array}$ & 4.5 & 4.00 & 4.00 & 4.17 & Acceptable \\
\hline C. Usability & 4.5 & 4.04 & 4.00 & 4.18 & Acceptable \\
\hline $\begin{array}{l}\text { 1. The software is easy to use } \\
\text { (learnability). }\end{array}$ & 4.5 & 4.15 & 4.00 & 4.22 & Acceptable \\
\hline $\begin{array}{l}\text { 2. The software is easy to operate } \\
\text { (operability). }\end{array}$ & 4.5 & 4.10 & 4.00 & 4.20 & Acceptable \\
\hline $\begin{array}{l}\text { 3. The software displays instructions that } \\
\text { are easy to understand } \\
\text { (understandability). }\end{array}$ & 4.5 & 4.11 & 4.00 & 4.20 & Acceptable \\
\hline D. Efficiency & 4.5 & 3.79 & 4.00 & 4.10 & Acceptable \\
\hline $\begin{array}{l}\text { 1. The software can easily execute the } \\
\text { requests (time behavior). }\end{array}$ & 4.5 & 3.85 & 4.00 & 4.12 & Acceptable \\
\hline $\begin{array}{l}\text { 2. The software uses minimal system } \\
\text { resources (resource behavior). }\end{array}$ & 4.5 & 3.52 & 4.00 & 4.01 & Acceptable \\
\hline $\begin{array}{l}\text { 3. The software determines the error or } \\
\text { bug encountered during operation } \\
\text { (analyzability). }\end{array}$ & 4.5 & 4.00 & 4.00 & 4.17 & Acceptable \\
\hline Overall/Grand Mean & 4.5 & 3.97 & 4.00 & 4.16 & Acceptable \\
\hline
\end{tabular}




\section{SUMMARY DF FINDINGS}

Based on the results of the study, the following findings were derived:

1. The developed system collaborates and consolidates requirements of different sub systems and is able to deliver the expected output in compliance to different external agencies (CSC, CHED, DBM). The system is also considered acceptable based on the following criteria:

a. Functionality. The software is adaptable as a solution to the problems in the current system. The system has the ability to interact with the system environment. Since there are 3 subsystems in SYSTEM, there are data that are interrelated and could work together with the use of query language for joining the tables. The software has provision to prevent unauthorized users from accessing the system. It has the privilege maintenance to different types of users based on the grants that are given by the administrator.

b. Reliability. The software could restore to its normal operation when failure occurs. It has error handlers that manage all possible errors.

c. Usability. The software is user friendly; easy to use and displays instructions that are easy to understand. The developer adapted the current forms and templates in designing the modules to help the users to easily use the system without having a problem with the sequence of instructions.

d. Efficiency. The software can easily execute the requests and uses minimal system resources.

2. The design of the database structure meets the requirements of the definition and manipulation of integrated systems in a single storage with the consideration of data security based on the privileges.

3. The system was considered acceptable and was recommended for implementation because of its capacity to meet the target of collaboration and consolidation of 3 subsystems that resulted to the reduction of tedious work. Thus, it would help the management to easily monitor the performance of the university as a whole and as well as the individual contributor.

\section{CONCLUSIONS}

Based on the results of the study, the following conclusions were derived:

1. The system could perform the correct cascading process in SPMS in terms of assigning and approval of SI, creating and approval of Commitments, creating and approval of actual performance, and the rating of outputs;

2. The system was designed and performed collaboration and consolidation of SPMS, NF, and OPIF that resulted to easy monitoring of the performance of the university and the consolidation of data from different forms. The data encoding in Normative Funding was reduced to $78 \%$ and the data encoding in OPIF was reduced to $48 \%$;

3. The system is secured in terms of the access privilege in using the system. The system is reliable in in providing reports, such as performance rating and monitoring results;

4. The system is designed from the requirements of TUP for SPMS, NF, and OPIF which was likewise based on the requirements that came from the CSC, CHED, and DBM.

\section{RECDMMENDATIONS}

After a thorough analysis of the results, the following recommendations were generated:

1. The system should be implemented on a per sector basis from top management to individual level;

2. The system should be used to define commitments for later evaluation of the actual performance;

3. More tests should be facilitated to improve the efficiency of the system and to identify possible enhancement of its functionality;

4. In-depth study to test whether the system project developed for TUP could be integrated to the existing system like ERS and Portal should be conducted;

5. The system should be maintained and monitored to identify possible errors that are not anticipated in the previous study.

6. Researches in other SUCs should be conducted for the possible implementation of the system in a national level with consideration on the availability of IT infrastructure. 


\section{PRACTICAL IMPLICATIONS}

This study can be used by different SUCs sectors in decision making on how to better improve the performance of the institution aligned with the Success Indicators assigned to academic sectors like Research Output, Instructional Materials, Extension Services, Alumni Tracer, and Faculty Development. The outcomes can be easily validated from the requirements set by CHED and can be easily verified based on the budget allotted by the DBM.

\section{REFERENCES}

Agranoff, R. (2005). Managing collaborative performance: Changing the boundaries of the state? Public Performance \& Management Review, 29(1), 18-45.

Akram, J. K. (2011). The significance of management information systems for enhancing strategic and tactical planning. JISTEM-Journal of Information Systems and Technology Management, 8(2), 459-470.

Atkinson, A. A., Waterhouse, J. H., \& Wells, R. B. (1997). A stakeholder approach to strategic performance measurement. Sloan Management Review, 38(3), 25.

Cadbury, A. (2006). Global corporate governance forum, work bank. Retrieved from www.o2.com/o2_glossary.asp

Civil Service Commission of the Republic of the Philippines. (2014). Strategic Performance Management System $(S P M S)$. Retrieved from http://www.csc.gov.ph/2014-02-21-08-16-56/2014-02-21-08-17-24/2014-02-28-0636-47.html

Delmas, M. A., Etzion, D., \& Nairn-Birch, N. (2013). Triangulating environmental performance: What do corporate social responsibility ratings really capture?. The Academy of Management Perspectives, 27(3), 255-267.

DeNisi, A., \& Smith, C. E. (2014). Performance appraisal, performance management, and firm-level performance: A review, a proposed model, and new directions for future research. Academy of Management Annals, 8(1), 127-179.

Dess, G. G., \& Robinson, R. B. (1984). Measuring organizational performance in the absence of objective measures: The case of the privately held firm and conglomerate business unit. Strategic Management Journal, 5(3), 265273.

Duque, F. (2012). Guidelines in the establishment and implementation of agency Strategic Performance Management System (SPMS). Retrieved from http://www.csc.gov.ph/2014-02-21-08-28-23/pdf-files/file/199guidelines-in-the-establishment-and-implementation-of-agency-strategic-performance-management-systemspms

Haag, S., \& Cummings, M. (2013). Management information systems for the information age (ninth edition). New York, NY: McGraw-Hill Education.

Hart, S. L. (1992). An integrative framework for strategy-making processes. Academy of Management Review, 17(2), 327-351.

Irving, R. H., Higgins, C. A., \& Safayeni, F. R. (1986). Computerized performance monitoring systems: Use and abuse. Communications of the ACM, 29(8), 794-801.

Kloot, L., \& Martin, J. (2000). Strategic performance management: A balanced approach to performance management issues in local government. Management Accounting Research, 11(2), 231-251.

Lausa, S. (2016). Operational efficiency of information technology and organizational performance of state universities and colleges in Region VI, Philippines. Asia Pacific Journal of Multidisciplinary Research, 4(4), 34-43.

Maneja, C., \& Tandang, N. (2012). Determinants in sustaining a local information system in the philippines: The case of the Barangay Management Information System (BMIS). The Journal of Public Affairs and Development, 1(2), 119-139.

Melville, N., Kraemer, K., \& Gurbaxani, V. (2004). Information technology and organizational performance: An integrative model of IT business value. MIS Quarterly, 28(2), 283-322.

O’Brien, J., \& Marakas, G. (2011). Management information systems for the information age (tenth edition). New York, NY: McGraw-Hill/Irwin.

Perry, W. E. (2007). Effective methods for software testing: Includes complete guidelines, checklists, and templates. Indianapolis, Indiana: John Wiley \& Sons.

Ten Asbroek, A. H. A., Arah, O. A., Geelhoed, J., Custers, T., Delnoij, D. M., \& Klazinga, N. S. (2004). Developing a national performance indicator framework for the Dutch health system. International Journal for Quality in Health Care, 16(suppl_1), i65-i71. 
Tonelli, A. O., Bermejo, P. H. D. S., \& Zambalde, A. L. (2014). Using the BSC for strategic planning of IT (information technology) in Brazilian organizations. JISTEM-Journal of Information Systems and Technology Management, 11(2), 361-378. doi: 10.4301/S1807-17752014000200008.

\section{Author's Biography}

Dr. Joel B. Mangaba is a graduate Bachelor of Science in Computer Science at STI College Novaliches, Master of Information Technology, and Doctor of Technology at TUP-Manila. Also, he earned units in Doctor of Technology major in Technology Management. Currently, he is a software professor of University of Makati, a Cofounder and Chief Financial Officer of BliThe Software Development, a Professorial lecturer of Graduate School of University of the East, Manila handling Advanced Statistical Methods and Seminar in IT for Society and Culture, a Professorial lecturer of Graduate School of Technological University of the Philippines and its consortia handling Management of Information System, a Research Reviewer of International Journal of Computing Sciences Research (IJCSR). He is a former professor of STI Academic Center Fairview, Chairman of BSIT, BSCS, and BSIS of University of the East Caloocan, a College Dean of STI College Ortigas-Cainta, a Systems Analyst of In-Demand Ideas IT Solutions, an acting Dean of St. Bernadette College, a professor of STI College Quezon Avenue and STI College Novaliches, an exam developer, and a thesis project evaluator of STI Headquarters. 